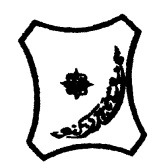

Bayero Journal of Pure and Applied Sciences, 12(1): 6 - 11

Received: June, 2017

Accepted: February, 2018

ISSN $2006-6996$

\title{
THERMOGRAVIMETRIC AND DIFFERENTIAL THERMAL INVESTIGATION OF RICE HUSK CELLULOSE
}

\begin{abstract}
Tenimu, A. A.
Department of Chemistry, FNAS, Sule Lamido University, Kafin Hausa, P. M. B. 048, K/Hausa, Nigeria. tendoha07@gmail.com; 08036331983.

ABSTRACT

A Cellulose isolation from rice husk waste was achieved through subjecting the bulk waste to a sequence of chemical processes and treatment. The rice husk cellulose was characterized using FTIR and thermal analysis. Investigation of the thermal decomposition of the cellulose sample was carried out using the technique of thermogravimetry (TGA) and differential thermal analysis (DTA). The FTIR chart diplayed characteristic peaks typical of cellulose moiety at 3386, 2899, 1632, 1318 and $1159 \mathrm{~cm}^{-1}$. The TGA curve showed the decomposition pattern of the cellulose with the onset temperature at around $275{ }^{\circ} \mathrm{C}$ and decomposition continuing up to $380^{\circ} \mathrm{C}$. The DTA showed inflection point determined by extrapolation at $380^{\circ} \mathrm{C}$. The range of thermal stability of this moiety provides requisite information for the choice of reaction procedure for the modification/functionalization of the cellulose.

Keywords: Cellulose, Thermogravimetric analysis, Differential thermal analysis, Rice husk, Agro-waste
\end{abstract}

\section{INTRODUCTION}

With the world cellulose consumption at about 95.6 million tons in 2015 and global demand expected to reach USD 36,968.8 million by 2020 (Researchandmarket, 2016), Nigeria with her enormous bioresource potential is placed at advantage to be a major player in this economic fortune of the cellulose market. However, at the moment, neither Nigeria nor any country in sub Sahara Africa is found on the map of world cellulose producers (Durbak, 1993). This is at a time the world is discouraging wood and other economic plants as bioresources. Cellulose is an organic substance abundant in plants with wide range of applications. Cellulose can be converted to several derivatives which result in increased application (Mench, et al., 1966; Heck, et al., 2004; Heinze \& Petzold-Welcke, 2012). There are several known sources from which cellulose have been derived, these include wood (Kenyazera et al, 2008), cotton (Frick Jr \& Robert, 1982), sugarcane bagasse (Sun, et al., 2004; Abdel-Halim, 2014; Li \& Ge, 2012; Liu, et al., 2007), rice straw (Das, et al., 2014; Kalita, et al., 2015), corn straw (Ping, et al, 2013; Kumar, et al., 2014), soyabean husk (Uesu, et al., 2000), non-edible fruit and seed (Meireles, et al., 2012; Achor, et al., 2014), banana stem (Omotosho \& Ogunsile, 2009) and etcetra

Auyo and Kafin Hausa communities in the Hadeija Emirate council of Jigawa state are major rice and sugarcane producers and qualifies Jigawa as a top rice producing state in Nigeria(Olawale, 2018). This partly account for the launch of the Dangote outgrower scheme by the Dangote Food Limited in conjuction with the Jigawa state government's Responsible Agricultural Investment (RAI) in the area. The scheme is expected to start with 20,000 hectre of rice cultivation to be expanded to 800,000 hectres over three years years(Committee, CDF II Technical, 2016; Dangote, 2016).

Today, the Danmodi Rice milling factory is unarguably the biggest producer of processed rice grain in this 'rice belt' within Jigawa state and arguably one of the biggest in Northern Nigeria. Information obtained locally at the factory in Kafin Hausa, reveals that rice husk $(\mathrm{RH})$ has a wide application in agriculture, where it served both as manure and animal feedstock. A mixture of finely divided rice husk and dried fish serve as poultry feed. It is used as bed layer as elevation for storing bagged rice, millet, corn, and other agricultural products because it can not be attacked by termite and other harmful insects. Rice husk is also used in heating and in local construction, $\mathrm{RH}$ mixed with clay soil is used in the building of mud houses.

These local applications of RH in Kaffin Hausa and environ have been replicated elsewhere and this have served as a driving force behind several scientific investigations globally. 
BAJOPAS Volume 12 Number 1, June, 2019

The research findings of the constituents of $\mathrm{RH}$ which is mainly cellulose and silicate material (Stefani, et al., 2015), has helped to justify the various roles played by $\mathrm{RH}$ in agriculture, construction, energy, etcetra. Lignin and cellulose have for instance been found to have a significant biological role in the nutritive value of animal feeds (Crampton \& Maynard, 1937). Cellulose therefore serve as a substance with potential application in the food, pharmaceutical, energy, construction, and especially have the great advantage of generating several other chemical feedstock with source from agrowaste. Isolation of $\mathrm{RH}$ cellulose for organic, inorganic and organometallic derivatization and nanonization of cellulose as well as their applications in energy; such as biofuel, fine chemical feedstock, drug delivery, water purification, catalysis, oil spill and general environmental remediation and etcetra are all current trends in the exploitation of cellulose from agricultural waste (Keshawy, et al., 2013; Hubbe, et al., 2012; Filho, et al., 2015; Saliba, et al., 2000; Kamel, et al., 2008).

A great chunk of $\mathrm{RH}$ is treated as waste and with Government effort toward self sufficiency in rice production, we expect a larger volume of this waste in the very near future. In several ways this waste is harmful to the environment. Proper handling of rice husk waste can yield cellulose, lignin and other products that are of immense benefit (Ramiah, 1970; Stefani, et al., 2015). The main interest of this work is the derivatization of inorganic/organometallic cellulose which can have useful application in phase transfer catalysis and biological chemistry as drug carriers. However, the current work is aimed at isolating cellulose from rice husk obtained from Danmodi Factory, characterise the cellulose using FTIR, thermogravimetry and differential thermal analysis.

\section{MATERIAL AND METHODS}

Reagents and solvents - potassium hydroxide, hydrochloric acid, and sodium metabisulfite were all analytical reagent grade, sodium hypochlorite was obtained as Jik (3.5 \% $\mathrm{m} / \mathrm{v}$ sodium hypochlorite) by Reckit Benckiser (Nig) Ltd.
Thermal analysis - thermogravimetric analysis and differential thermal analysis was carried out using Perkin Elmer, TGA 4000 thermogravimetric analyzer. $20 \mathrm{mg}$ of cellulose sample was heated from $30{ }^{\circ} \mathrm{C}$ to $950{ }^{\circ} \mathrm{C}$ under nitrogen flow at 10 ${ }^{\circ} \mathrm{C} / \mathrm{min}$.

FTIR spectra was recorded using a Agilent Cary 630 FTIR spectrometer. The spectrum was collected from $4000-650 \mathrm{~cm}^{-1}$ at a resolution of $8 \mathrm{~cm}^{-1}$ with an accumulation of 10 scans.

Preparation of crude sample

$\mathrm{RH}$ was obtained as bulk waste from Danmodi Factory, the RH was washed thoroughly under running tap water with continuous stirring. After washing, the $\mathrm{RH}$ was air dried. The dry material was milled. The powder was passed through 100 mesh size sieve and stored in plastic containers. Extraction of Cellulose

$20 \mathrm{~g}$ of $\mathrm{RH}$ powder in $250 \mathrm{~mL}$ of $3 \%$ (w/v) of $\mathrm{KOH}$ was stirred and left to boil for 30 minutes with continuous stirring. The mixture was then left to stand overnight then filtered and the residue was washed twice with distilled water and $100 \mathrm{~mL} 10 \%(\mathrm{v} / \mathrm{v}) \mathrm{HCl}$ was added. The organic part retained in the residue which contain cellulose was treated with sodium hypochlorite $0.7 \%(\mathrm{w} / \mathrm{v})$ at a ratio of $1: 50 \mathrm{~g}$ solid /mL liquor at $\mathrm{pH} 4$ and kept boiling for $2 \mathrm{~h}$. the solid was further treated with $5 \%(\mathrm{w} / \mathrm{v})$ sodium bisulphite solution at room temperature for $1 \mathrm{~h}$ using a solid to liquor ratio of $1 \mathrm{~g} / 50 \mathrm{ug}$ and then washed with distilled water and dried at $80{ }^{\circ} \mathrm{C}$ in the oven. It was then treated with $17.5 \%(w / v)$ of $\mathrm{NaOH}$ solution at room temperature for $8 \mathrm{~h}$ using a solid to liquor ratio of $1 \mathrm{~g} / 50 \mathrm{~mL}$, washed and dried at $80{ }^{\circ} \mathrm{C}$ (Stefani, et al., 2015; Brendel, et al., 2000).

\section{RESULTS AND DISCUSSION}

FTIR Analysis

A white insoluble dissolving pulp was obtained. The alpha cellulose displayed characteristic vibrational absorbance at 3386, 2899, 1638, 1318 , and 1159 as shown in the spectrum of the $\mathrm{RH}$ cellulose in figure 1 , the bands are generally associated with cellulose moiety and is very useful in cellulose identification (Sun, et al., 2004). 


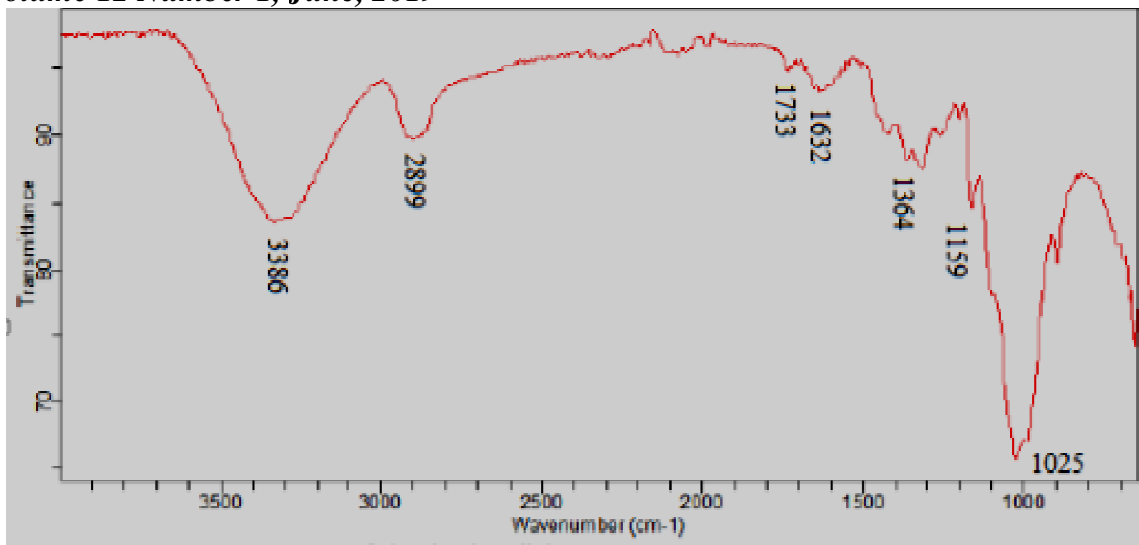

Figure 1. FTIR spectra of rice husk cellulose

The peak observed at $1632 \mathrm{~cm}^{-1}$ is assigned to $\mathrm{OH}$ bending vibration of absorbed water, this is typical of cellulose. The hydroxyl and $\mathrm{C}-\mathrm{H}$ of methylene group stretching vibrations are displayed at $3386 \mathrm{~cm}^{-1}$ and $2899 \mathrm{~cm}^{-1}$ respectively. The peak at $1364 \mathrm{~cm}^{-1}$ is assigned to the asymmetric vibration of the methylene group. The peak at $1733 \mathrm{~cm}^{-1}$ corresponding to vibrations of acetyl and uronic ester groups is identified as hemicellulose band. The presence of this band indicates that the procedure for the cellulose isolation did not effectively eliminate hemicellulose. However, the absence of absorption bands from $1500-1595 \mathrm{~cm}^{-1}$ in the spectra indicate the successful dewaxing process, assuring total removal of lignin.
Thermal Analysis

The thermal analysis was carried out using a TGA 400 thermogravimetric analyzer. The TGA/DTA analyzer can be conveniently used for the investigation of the thermal behavior of cellulose. RHC has been reported to show major thermal decomposition peak of the cellulose at around $362{ }^{\circ} \mathrm{C}$ (Stefani, et al., 2015), just as native sugarcane bagasse cellulose is reported to start thermal decomposition at $245{ }^{\circ} \mathrm{C}$ at 50 $\%$ weight loss with the major decomposition at $339^{\circ} \mathrm{C}$ (Liu, et al., 2007). The extrapolated onset temperature $\left(T_{0}\right)$ for the TGA curve of the RHC for the current work is $270{ }^{\circ} \mathrm{C}$ as displayed in figure 2 .

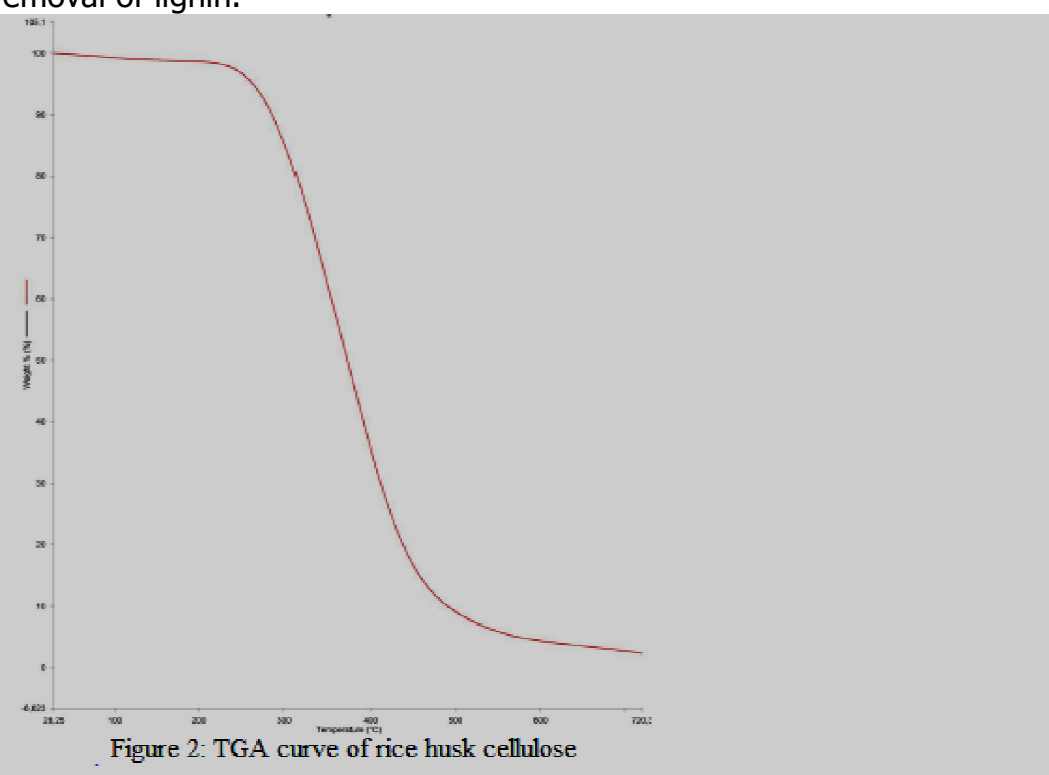

It can be observed that there is a significant mass loss at around $275^{\circ} \mathrm{C}$ with mass percent of $92 \%$ reaching around $380{ }^{\circ} \mathrm{C}$ at $54 \%$ weight loss. The extrapolated onset temperature is reproducible and specified to be used by the ASTM

The DTA/TGA curve of the RHC (figure 3), shows a weight loss around $100{ }^{\circ} \mathrm{C}$ corresponding to vaporization of absorbed water which could not be given off completely on drying (Ramiah, 1970), it further displayed a deep endotherm around $380^{\circ} \mathrm{C}$ corresponding to the rapid mass loss, as in the TGA curve ascribed to the decomposition of the cellulose polymer. 
BAJOPAS Volume 12 Number 1, June, 2019

This is the first derivative peak temperature (Tp) calculated during the thermal analysis, it the greatest rate of change on the weight loss indicates the inflection point, the point at which

curve in figure 3 occurred.

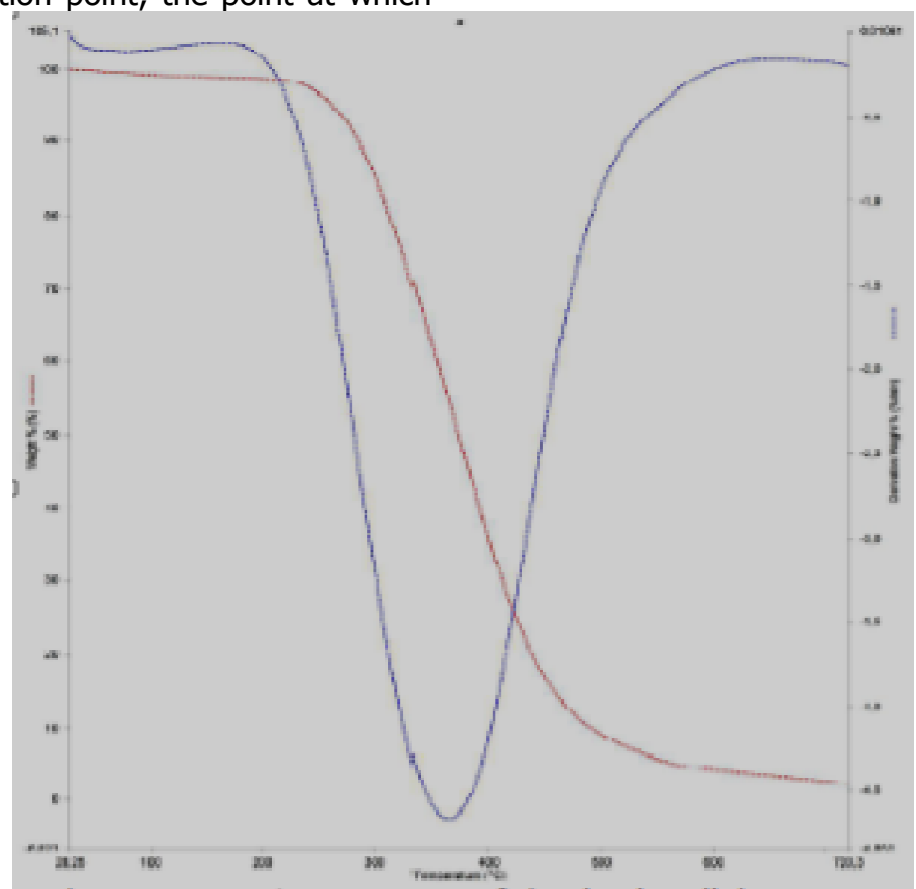

Figure 3: TGA/DTA curve of rice husk cellulose

This observation is in agreement with earlier report that cellulose decomposition usually start at around $275{ }^{\circ} \mathrm{C}$ and continue up to $380{ }^{\circ} \mathrm{C}$ (Stefani, et al., 2015). The complete decomposition at below $400{ }^{\circ} \mathrm{C}$, further prove the complete delignification process as lignin decomposition would have tailed up to around $550{ }^{\circ} \mathrm{C}$. The exclusion of air in the analysis guaranteed a non-oxidative atmosphere which would have given rise to pyrolysis products and hence generate a complicated thermogram useful only for reaction studies (Akita \& Kase, 1967).

\section{CONCLUSION}

Cellulose modification before now is largely via grafting/copolymerization without necessarily dissolving the solid or making use of the expensive ionic liquid (Marsh, et al., 2009) or other enviromentally unfriendly solvents such as pyridine (Malm, et al., 1957). More recently, cellulose dissolution have been achieved by the use of aqueoeus mixture of alkali hydroxide and urea (Gu, et al., 2007; Isogai \& Atalla, 1998). Synthetic functionalization of cellulose and cellulosics through this enviromentally friendly route require a good knowledge of the thermal property of the cellulose material to help in making the correct choice of reaction protocol. This is quite necessary since unnecessary heating can easily destroy the chemical nature of cellulose; and posibly jeopardising the dream of making cellulose material a material of choice for deriving fine chemicals. With the detailed information now available on the thermal behaviour of cellulose derived from rice husk waste in Kafin Hausa, Nigeria, further efforts can now be made at solubilizing the moiety and making useful derivatives out of it.

Though not fully characterized, the high yield of inorganic silicate product seperated during this isolation is a pointer to the dangerrice husk waste might portend to agricultural practices in this community. However the positive implication explains why the waste is useful in fortifying clay soil for local building construction purposes.

\section{ACKNOWLEDGEMENT}

The author is grateful for the financial support for this research work from Sule Lamido University for the Research Grant Ref., No. SLU/R/193/VOL.1. The author is also grateful to the management of Danmodi Farm for permission to collect the sample for this research. 


\section{REFERENCES}

Abdel-Halim, E. S. (2014). Chemical modification of cellulose extracted from sugarcane bagasse: Preparation of hydroxyethyl cellulose. Arabian Journal of Chemistry, 7(3), 362-371.

Achor, M., Oyeniyi, Y. J., \& Yahaya, A. (2014). Extraction and characterization of microcrystalline cellulose obtained from the bark of the fruit of Lageriana siceraria (water gourd). Journal of Applied Pharmaceutical Science, 4(01), 057 - 060.

Akita, K., \& Kase, M. (1967). Determination of Kinetic parameters for pyrolysis of cellulose and cellulose treated aith ammonium phosphate by differential thermal analysis and thermal gravimetric analysis. Journal of Polymer Science: Part $A-1,5,833-848$.

Brendel, O., Iannetta, P. P., \& Stewart, D. (2000). A Rapid and Simple Method to Isolate Pure Alpha-Cellulose. Phytochem. Anal., 11, 7-10.

Committee, CDF II Technical. (2016). Comprehensive Development Framework. Dutse: Jigawa State Government. 1-167

Crampton, E. W., \& Maynard, L. A. (1937). The relation of cellulose and lignin content to the nutritive value of animal feed. Journal of Nutrition, 15(4), 383-395.

Dangote, A. (2016, February 21). My-rice-for all project. Vanguard Nespaper.

Das, A. M., Ali, A. A., \& Hazarika, M. P. (2014). Synthesis and characterization of cellulose acetate from rice husk:Ecofriendly condition. Carbohydrate Polymer, 112, 342 - 349.

Durbak, I. (1993). Dissolving pulp industry: Market trends. Gen. Tech Rep. FPL-GTR77. Madison WI: Madison: U.S. Department of Agriculture, Forest Service, Forest products Laboratory.

Filho, G. R., Almeida, F., Ribeiro, S. D., Tormin, T. F., Munoz, R. A., Assuncao, R. M., \& Barud, H. (2015). Controlled Release of Drugs from Cellulose Acetate Matrices Produced from Sugarcane Bagasse: Monitoring by square-wave Voltametry. drug Development and Industrial Pharmacy, 1-7.

Frick Jr, J. G., \& Robert, H. J. (1982). Crosslinking cotton cellulose with Aldehydes. Journal of Applied polymer Science, 27, 983 - 988.

Gu, L., Jin, H., \& Zha, C. (2007). Direct dissolution of cellulose in
$\mathrm{NaoH} /$ thiourea/urea aqueous solution. Carbohydrate Research, 342, 851-858.

Heck, J., Zhang, F., \& Vill, V. (2004). CelluloseBased polymer with long chain pendant ferrocene derivatives as organometallic chromophores. Organometallics, 3, 3853-3864.

Heinze, T., \& Petzold-Welcke, K. (2012). Recent Advances in Cellulose Chemistry. In Y. Habibi, \& L. A. Lucia, Polysaccharide Building Blocks: A Sustainable Approach to the Development of Renewable Biomaterials (1st ed., pp. 1 - 50). New York: John Wiley \& Sons Inc.

Hubbe, M. A., Payne, K. C., Jackson, C. D., Aizpurua, C. E., \& Rojas, O. J. (2012). Oil Spills Abatement, Factors Affecting Oil Uptake by Cellulosic Fibers. Environ. Sci. Technol., 46, 7725-7730.

Isogai, A., \& Atalla, R. H. (1998). Dissolution of cellulose in aqueous $\mathrm{NaOH}$ solutions. Cellulose, 5, 309-319.

Kalita, E., Nath, B. K., Deb, P., Agan, F., Islam, M. R., \& Saikia, K. (2015). High quality fluorescent cellulose nanofibers from endemic rice husk:Isolation and characterization. carbohydrate Polymer, $122,308-313$.

Kamel, S., Ali, N., Jahangir, K., Shah, S. M., \& El-Gendy, A. A. (2008). Pharmaceutical Significance of Cellulose: A Rewiew. eXPRESS Polymer Letters, 2(11), 758778.

Kenyazera, N. V., Konshin, N., Chemeris, N. A., \& Chemeris, M. M. (2008). Synthesis of Cellulose Esters with Aliphatic Hydroxy acids from Aspen Wood. Russian Journal of Applied Chemistry, 81(6), 1087 1089.

Keshawy, M., El-Hamouly, S. H., Abdul-Raheim, M. A., Kabel, K. I., \& Abdel-Moghney, T. (2013). Synthesis of oil spill sorbents based on cellulose derivatives. Journal of Dispersion Science and Technology, 34(11), 1507-1516.

Kumar, C. G., Kumar, M. P., Gupta, S., Sunder, M. S., Rao, K. V., Jagadeesh, B., . . . Kamal, A. (2015). Isolation and characterization of cellulose from sweet sorghum. Sugar Tech. 17(4), 395-403.

Li, Z., \& Ge, Y. (2012). Antioxidant activities of lignin extracted from sugarcane bagasse via different chemical procedures. International Journal of Biological Macromolecules, 51, 1116 - 1120.

Liu, C. F., Sun, R. C., Zhang, A. P., \& Ren, J. L. (2007). Preparation of sugarcane bagasse cellulosic phthalate using an 
BAJOPAS Volume 12 Number 1, June, 2019 ionic liquid as reaction medium. Carbohydrate Polymer(68), 17 - 25.

Malm, C. J., Mench, J. W., Fulkerson, B., \& Hiatt, G. D. (1957). Preparation of Phthalic Acid Esters of Cellulose. Industrial and Engineering Chemistry, 49(1), 84-88.

Marsh, K. N., Pinkert, A., Pang, S., \& Stangler, M. P. (2009). Ionic Liquids and their Interaction with Cellulose. Chem. Rev., 109, 6712-6728.

Meireles, C. S., Viera, J. G., Fliho, G. R., Faria, F. A., Gomlde, D. D., Pasquini, D., . . . Motta, L. A. (2012). Synthesis and characterization of methylcellulose from cellulose extracted from mango seeds for use as mortar additive. Polimeros, 22, 80-87.

Mench, J. W., Fulkerson, B., \& Hiatt, G. D. (1966). Valeric esters of cellulose. I \& EC Research, 2(2), 110-115.

Olawale Sherif;. (2018, February 11). NAIJAQUEST.COM. Retrieved March 30, 2019, from List of Rice producing states in Nigeria and all you need to know: https://naijaquest.com/rice-producingstates-in-nigeria/

Omotosho, M. A., \& Ogunsile, B. O. (2009). Fibre and chemical properties of some Nigerian grown Musa Species for pulp production. Asian Journal of Material Sciences, 14 - 21.

Ping, N., Dan, L., Zhen, Z. F., Jing, L. Y., \& Wang, N. (2013). Preparation and characterization of cellulose fibres from corn straw as natural oil sorbents. $I \& E$ Research, 52, 516-524.
Ramiah, M. V. (1970). Thermogravimetric and differential thermal analysis of Cellulose, Hemicellulose and Lignin. Journal of Applied Polymer Science, 14, 13231337.

Researchandmarket. (2016). Cellulose Fiber Market by Application \& by Region Trends \& Forecasts to 2020. Retrieved from

http://www.researchandmarkets.com/re ports/3439243/

Saliba, R., Gauthier, H., Gauthier, R., \& PetitRamel. (2000). Adsorption of Copper(II) and Chromium(III) ion onto Amidoximated cellulose. Journal of Applied Polymer Science, 75, 16241631.

Stefani, P. M., Marin, D. C., Vecchio, A., Luduena, L. N., Fasce, D., \& Alvarez, V. A. (2015). Revalorization of rice husk waste as a source of cellulose and silica. Fibres and Polymers, 16(2), 285-293.

Sun, R. C., Sun, J. X., Sun, X. F., \& Zhao, H. (2004). Isolation and characterization of cellulose from sugarcane bagasse. Polymer degradation and stability, 84, 331-339.

Uesu, N. Y., Pineda, E. A., \& Hechenleitner, A. A. (2000). Microcrystalline cellulose from soyabean husk: effects of solvent treatments on its properties as acetylsalicylic acid carrier. International Journal of Pharmaceutics, 206(1-2), 8596. 